Journal of Social Research and Behavioral Sciences

Original Article

Received/Accepted Dates

20.12.2021/28.02.2022

DOI: $10.52096 /$ jsrbs.7.14.21
Sosyal Araştırmalar ve Davranış Bilimleri Dergisi

ISSN:2149-178X

Volume: 7 Issue: 14 Year: 2021

\title{
Ĕ̆itim Yönetiminde Örgütsel Özdeşleşme Modellerinin İncelenmesi
}

Bünyamin Özdemir

Millî Eğitim Bakanlı̆̆ı Eğitim Yöneticisi

bunyamin.ozdemir@hotmail.com

ORCID:0000-0001-4618-2279

\author{
Dr. Fatma Özge Çavuş Bekce \\ Millî Eğitim Bakanlı̆̆ Rehber Öğretmen \\ karmate06@gmail.com
}

ORCID: 0000-0002-6404-1923

\section{Özet}

Örgütün başarısı ile başarısızlı̆̆ını kendine aitmiş gibi yaşaması ile bireyin kendisini örgüt ile bir bütün olarak algılaması duygusu özdeşleşmedir. Bir öğretmenin okula kendini ait hissetmesi, okulun başarısını kendi başarısı olarak algılaması, kendini okuluyla bir bütün olarak hissetmesi öğretmenin okulla özdeşleştiğine işarettir. Öğretmenin mesleğini ehemmiyet vererek, öz verili biçimde yapmalarında örgütleri ile özdeşim kurmalarının rolü yadsınamazdır. Öğrencilerin bireysel gelişimlerinin desteklenmesi, akran ilişkilerinde veya istenmeyen davranışlarda onların doğru yönlendirilmesi, bağımsız birer birey olarak yetiştirilmesinde ve de öğrenme ortamını en verimli şekilde değerlendirmesinde öğretmenlerin oldukça fazla bir rolü vardır.

Anahtar Kelimeler: Eğitim Yönetimi, Özdeşleşme, Örgütsel Özdeşleşme 


\begin{abstract}
Identification is the feeling of experiencing the success and failure of the organization as if it is their own, and the individual's perception of himself as a whole with the organization. A teacher's feeling of belonging to the school, perceiving the success of the school as his own success, feeling himself as a whole with his school indicate that the teacher identifies with the school. The role of teachers' identification with their organizations in their self-sacrificing and self-sacrificing performance is undeniable. Teachers have a very important role in supporting the individual development of students, directing them correctly in peer relations or undesirable behaviors, raising them as independent individuals and evaluating the learning environment in the most efficient way.
\end{abstract}

Keywords: Educational Administration, Identification, Organizational Identification

\title{
Giriş
}

Eğitim, insanların davranışlarında olumlu düzeyde fark yaratacak gelişimleri hedefleyen etkileşimli bir süreçtir. Bu süreçte eğitim bireyi, birey ise gelişen özellikleri ile toplumu doğrudan etkiler. Eğitim sürecinin belirlenen hedefleri gerçekleştirmesi etkili örgütsel yapıların varlığına bağlidır.

Toplumlar yaşamlarını nitelikli bir şekilde devam ettirebilmek ve geleceklerini güvence altına alabilmek için kendi eğitim sistemlerini oluşturmalarının yanı sıra oluşturdukları sistemi çağa uygun olacak şekilde sürekli değiştirmek ve geliştirmek durumundadır (Yılmaz, 2008).

Eğitim sistemlerinin merkezinde yer alan okul ortamlarından beklenen nitelik algısı günden güne değişmektedir. Çağımızda eğitim süreçlerinin sadece akademik başarı bağlamında değil, aynı zamanda öğrencilerin duygusal ve sosyal gelişimlerini destekleme bağlamında da önemli görülmesi eğitim örgütlerinde etkililik beklentisini öne çıkarmıştır. Eğitim sürecinin belirlenen hedefleri gerçekleştirmesi etkili örgütsel yapıların varlığına bağlıdır (Sönmez, 2005). 
Kişilerin amaçları ile örgütün amaçlarının uyumlaşması ve bütünleşmesi süreci örgütsel özdeşleşmedir. Bir bireyin benliğinin örgüt üyeliğine ne derece bağılı olduğu, onun örgütsel özdeşleşme düzeyini belirler (Kanten, 2012).

Birey için örgüt üyeliği kişiliğinde önemli bir yer edinmiş ve sosyal anlamda sosyal ilişkilerinden daha ileri bir boyuta geçmişse birey örgüt ile ileri seviyede özdeşim kurmuş demektir (Karabey ve İşcan, 2007).

$\mathrm{Bu}$ düzeyde örgütsel özdeşleşmeye sahip olan kişiler, örgütsel amaçlarını kendi hedefleri gibi kabul etmekte, yalnız kendi amaçları için çalışmak yerine bütün örgüte fayda sağlayacak işlere odaklanmaktadır. Bu nedenle kişileri birlikte çalışmaya ve işbirliğine katkı sağlayacak faaliyetlere yönlendirmek güçlü bir özleşmenin amacıdır (Yaykıran, 2020).

\section{Eğitim Yönetiminde Örgütsel Özdeşleşme}

\section{Örgütsel Özdeşleşmenin Kavramsal Çerçevesi}

Özdeşleşme, birey ve aidiyet hissettiği örgütle arasında bulunan ilişkiselliği izah etmenin en akılcı yöntemidir. Çoğunluk ile örgüt bağl1lı̆̆1 ve örgüt vatandaşlığı davranımı türünde yapılar ile karşılaştırılması, tutarsızca tanım olmasından kaynağını almaktadır.

Bireyin kendini bir örgüte dâhil hissetmesi özdeşleşmenin başladığına işarettir. Bu süreçte birey örgütün değer ve amaçlarını benimser ve kendi amaçlarıyla ilişkilendirir. Birey benlik olarak örgüt üyeliğini içselleştirdiğinde bir bağl1lık ve anlam duygusu hisseder. Bu yüzden özdeşleşme kavramı örgüt ortamında çalışan bireylerin davranışlarının açıklamada rehber olarak kullanılabilir (Karabey, 2005).

Bir kişinin özdeşleşme olgusunun var olabilmesi için birbiriyle bağlantılı olan ve özdeşlemenin tamamlayıcıları olan üç özelliğe sahip olması gerekir. Bunlar; sadakat, üye olmak ve benzerlik duygularıdır.

Sadakat; bireylerin diğerleri tarafindan paylaşılan amaç ve politikaları destekleyecek şekilde bağl1lık hissetmesi iken üye olmak; kişinin aitlik hissini hissedeceği bir birliktelik duygusudur, 
Benzerlik ise insanın, diğer bireylerle aynı amaçlara sahip olması olarak ifade edilebilir (Tüzün, 2006).

Özdeşleşme süreci benzeşme (örgüt değerleriyle kendi değerlerini benzer bulma) ya da öykünme (örgüt değerlerine uyma) süreci olarak da görülebilir. Özdeşleşme sonucunda bireyin uyma ya da öykünme davranışının temelinde uyulan şeyin değerli olduğu fikri yatar. Bireyin gözünde uyulan şeyin değeri var olduğu sürece uyma davranışı devam eder. Bir bireyin, önemsediği kişilere benzeme, onlar gibi olduğunu algılaması özdeşleşmenin fayda sağladığının göstergesidir (Kağıtçıbaşı, 2004).

Örgütlerin çalışanlarla olan psikolojik ilişkileri her geçen gün daha çok önem kazanmaktadır. Buna bağlı olarak örgüt ve çalışanların birbirlerinden beklentileri de zamanla değişmektedir. İnsanlar önceleri kendilerini isimleriyle veya yaptığı işlerle özdeşleştirirken artık çalıştıkları örgütle özdeşleştirmektedirler (Tokgöz, 2012).

Günümüzde örgütler çalışanlarından iş yerlerini daha çok sevme, iş yerindeki herkesle dayanışma içerisinde olma, sadakat duygusuna sahip olma gibi özelliklerin beraberinde örgütü bireysel kimlikleriyle özdeşleştirecek derecede benimsemelerini beklemektedir (Polat ve Meydan, 2010). Birlik ve beraberlik hissi ile çalışanlar belirsizlik duygularını ve aidiyet gereksinimlerini gidermek için örgütleriyle özdeşleşirler. Bu durum onların birbirlerine yaklaşmasına ve örgüte entegre olmalarını sağlar (Tüzün ve Çağlar, 2008).

Örgütleriyle özdeşleşenler örgüte faydalı olabilmek için daha fazla sorumluluk alıp daha fazla çalışmaktadırlar, bu durum onların motivasyonlarını da artırır. Sorumluluk duygusuyla çalışmanın yüksek düzeyde verim getirdiği düşüncesi ile örgütsel özdeşleşme giderek önem kazanması muhtemeldir (Balc1 vd., 2012).

Kişinin kendisini bütünün parçası olarak hissetmesi, bireylerin diğer kişilerin davranış, değer ya da amaçlarını içselleştirebilmesi, bir nesnenin diğer bir nesneyle sınıflandırılması örgütsel özdeşleşmenin tanımları arasındadır (Karabey, 2005).

Buradan da görüldüğü gibi tanımların ortak yanı bireyin benliği açısından birey-örgüt ilişkisini temel alması ve bireyin benliği üzerindeki konumu itibariyle örgüt üyeliğinin etkisi farklı açılardan incelenmiş olmasıdır. 


\section{Örgütsel Özdeşleşme Modelleri}

Örgütsel özdeşleşme kavramı, 1980’li yıllarda tanımlanmaya ve diğer kavramlardan ayrışmaya başlamış, sonrasında ise sosyal kimlik kuramı çalışan araştırmacılar tarafından farklı modellerle geliştirilmiştir. Geliştirilen bu modeller, kişinin örgüt ile olan psikolojik bağını ve örgütle olan özdeşleşmenin hangi durumlarda değiştiğini anlatmaktadır (Tümer, 2010).

Özellikle örgütsel özdeşleme ile ilgili dört model önem arz etmektedir. Bunlar; 1998'de Scott, Corman ve Cheney'ın geliştirmiş olduğu Yapısal Özdeşleşme Modeli, 2001'de Kreiner ve Ashforth'ın geliştirmiş olduğu Geliştirilmiş Özdeşleşme Modeli, 2004'te Reade'ın geliştirmiş olduğu Özdeşleşme Modeli ve 2006'da Ashforth ve Mael'nn geliştirmiş olduğu Örgütsel Özdeşleşme Modelidir.

\section{Scott, Corman ve Cheeney'ın Yapısal Özdeşleşme Modeli}

$\mathrm{Bu}$ modellemede örgütteki çokluca özdeşleşmenin yapısallı̆̆ yapılanmanın kuramsal çerçevesi şeklinde ele alınmaktadır. Bu kuramda özdeşleşme ile kimlik arasındaki ilişkiye vurgu yapılmaktadır. Kimlik, bireyin amaç ile bağlantısını gösteren kapalı ya da açık sosyal davranışları ile oluşurken, örgütsel özdeşleşme ise kimliği belirleyen bu davranışlar ile oluşan sosyal ve dinamik bir süreci ifade eder. Özdeşleşmenin oluşumu ise bu örgütsel kimlik yapısının kişi tarafindan kabul edilmesi ile sağlanmaktadır (Çubukçu vd., 2012).

Adanmışlık kavramı; sadakat, bağlılık, örgütsel özdeşleme gibi pozitif sonuçlar oluşturduğu için bu modelde özellikle ele alınmaktadır. Bu özelliği ile pek çok araştırmacı bu modeli önemsemektedir. Burda özdeşleşmenin süreç boyutu 3 temelde irdelenmiştir (Scott vd., 1998)

\section{a. Yapının İkiliği}

$\mathrm{Bu}$ modellemedeki mesleki kimlik; profesyonel işbirlikleri veya iş türleri açısından bir kişinin gerçekleştirdiği eylemlerin etkisiyle ilişkili saygın oluşunu belirtmektedir. Kişisel kimlik ise; 
bireyin kendi mutlu olma halinin sosyal saygınlığından daha üstte önde olduğunu ileri sürmektedir (Scott vd., 1998).

\section{b. Yapının Bölgeselliği}

İçinde bulunulan her örgüt içinde farklı kültürler barındırmaktadır. Örgütsel özdeşleşmenin amacı birbirinden farklı olan bu kültürleri bütünleştirip homojen bir hale getirmektedir (Webber, 2011).

\section{c. Durumsal Eylem}

Özdeşleşmenin duruma göre değişmesi ve kişilerin hangi zamanlarda özdeşleşmesi gerektiği sorusuna cevap verme amaçlı geliştirilen durumsal eylem, modelin en önemli süreci olarak görülmektedir (Scottvd, 1998). Başka bir deyişle kişinin, içinde bulunulan durumdan etkilenme düzeyinin özdeşleşme seviyesi ile doğru orantılı olarak gerçekleştiğini belirtmektedir. Beklenmeyen kriz durumları yaşandığında örgütte bulunan bireylerin örgüte destek olma ve birlik olma istekleri artmakta ve bu şekilde yüksek örgüt özdeşleşmesi sağlanmaktadır.

Bryant ve Jary (1989) açısından yapılanma teorisinin en belirgin odağı tüm sosyal sistemlerin zaman ve mekan açısından incelenmesinin gerekliliğidir. Giddens (1976) ise sistemi, eylem ve yapıyı birbirine bağlayan olgu olarak adlandırmaktadır. Sistemler sürekli yeniden üretildikleri için zaman ve mekandan soyut olarak düşünülemezler (Silah, 2001).

Sosyal yaşam, çalışanların günlük yaşam rutinleri içerisinde örgütün müşterek paylaşım alanlarında oluşmakta, bu alanlarda bireyler, kim olduklarını anlayabilmek adına birbirleri ile karşılaştıkları bu günlük rutin faaliyetlerinden yararlanmaktadır. Dolayısıyla örgütsel özdeşleşme, sistem düzeyinde bir yapı olarak, örgütsel amaçlara bağlılığı belirten davranışlarda ortaya çıkmaktadır (Temel, 2001).

Bir ya da birden fazla örgütsel amaca dayalı olan bu modellemede özdeşleme ve kimlik düzeyinin duruma ve zamana göre değişebileceği ileri sürülmektedir. 


\section{Reade’nin Temel Özdeşleşme Modeli}

Örgütler çoğunlukla bireylerce hakim bir güç ve aygıt şeklinde her ne kadar algılansa da yapılmış bulunan birçok deney çalışmaları örgüt ile alakalı bir takım değişik özdeşleşme yapılarının olduğunu ortaya koymaktadır (Ashforth vd., 2008).

Temel özdeşleşme modelinin mimarı olan Reade, iki veya çiftli özdeşleşme biçiminde tanımladığı bu yapıya karşı mani bulunmak amacı ile bütün örgütün genel anlamı ve örgüt içerisinde çalışmalarda bulunan gurupların özdeşleşme derecesi ve öncül fonksiyonları üstünde çalışmalarda bulunmuştur (Reade, 2001).

Burada özdeşleşmeyle ilgili kavramı meydana koyan öncüllerse değişmemektedir, fakat iki veya çiftli seviyede bulunan bütün örgütün genel anlamı ve örgüt içerisinde yer alan özdeşleşme derecesi değişebilmekte ve yenilenebilmektedir (Reade, 2001).

\section{a. Ayırt Edici ve Prestij Özellikler}

Sosyal kimlikle ilgili teoriye göre birey, kendisine özgün niteliği bulunan prestijli guruplara kaydolmayı arzulamaktadır. Bununsa nedeni bu tarz gurupların, bireylerin hususi menfaatlerini kazanmasına imkan tanırken, öz güveninin yükseltilmesidir. Ayırt ediciliği olan özelliklerse, bir gurubu diğerlerinden farklılaştırmaktadır ve bireyin kendisini başkasına yönelik tanımlamasında kullandığı kesif ve açık çizgileri meydana getirmektedir (Ashforth vd., 2008).

\section{b. Yönetici Destekleri ve Takdirleri}

Bireylerin üst düzeyli yöneticiler ile ilişkiselliği, yüksek mesafeye ve görece az iletişimselliğe dayandığı için çok fazla hassas ve dolayısı ile üst düzeyli yönetimlerin destekleri ve takdirlerini alma çok müşkülatlıdır. Fakat kişiler arası dinamik, iletişimsel kolaylık ve mesafenin yakın olması nedeni ile bireylerin ilk yöneticisiyle arasındaki gündelik şeklide çok fazla kesif ilişkisellik bulunmaktadır (Karabey, 2005). 
Bireyin ilk yöneticisince örgütün hakkında görüşünü dillendirmeleri hususunda cesaretlendirilmesi ve bu sebeple kendisini saygınca, itibarlıca, güvenilirce hissetmesi örgüte ve üst yönetimlere yönelik olumlu duyguduruma ve tutum ve davranışlara sebebiyet vermektedir Kağıtçıbaşı, 2004).

\section{c. Kariyer Geliştirme Fırsatı}

Bireylerin örgütün içersindeki hususi gelişimlerini belirtmekte ve bireyler açısından kariyerle ilgili potansiyellerini arttırmak, kariyerlerini tamamlamak ve terfiyle kariyerle ilgili gelişimlerini sağlamak manasına gelmektedir. Kariyerle ilgili gelişimler, bireylerin başarma memnuniyetlerini yansıtırlar ve özdeşleşmeyle bireyleri örgütün aslı unsuruna bağlarlar (Polat ve Meydan, 2010).

\section{Kreiner ve Ashforth'ın Geliştirilmiş Özdeşleşme Modeli}

Kreiner ile Ashforth'un (2004) özdeşlemeyle ilgili kavramı, geliştirilmiş özdeşleşme modeli ile modellerin diğerlerinden değişik şekilde ifade etmişler ve geliştirmiştir. Kreiner ile Ashforth'a göre örgütün değer ve yargılarıyla çalışan kişilerin değer ve yargılarının benzer olma seviyesi özdeşleşme türünü meydana çıkarmaktadır.

Kreiner ile Ashforth'un (2004) geliştirilmiş özdeşleme modellemesinde özdeşleşememek, özdeşleşmek, kararsızca özdeşlemek ve tarafsızca özdeşlemek şeklinde dört değişik psikoloji durumundan bahsetmiştir. Bunları şu şekilde açıklayabiliriz:

\section{a. Güçlü Özdeşleşmek}

Örgütlerin amaç ve yöntemlerinin bireylerin hedefleri ile fazda bütünleşmeleri ve uyumsama vetiresidir. Güçlü özdeşleşme bağıyla yöneticiler ve çalışanlar arasındaki bağlantılar ivme kazanmakta bu da örgütsel anlamda proaktif bir başarı seviyesini beraberinde getirmektedir. 


\section{b. Özdeşleşmemek}

Özdeşleşmek tanımına karşı tanımlama değil, bunun aksi olarak bireylerin kimliklerinin örgütlerden ayırılması neticesinde meydana gelir. Bununla ilgili mevcut yapı örgütün içsel durumu bakımından istenen gelişme olarak kabul edilemez, zira çatışma ve zıtlıklara sebebiyet vermektedir (Temel, 2016).

\section{c. Kararsız Özdeşleşme}

Çalışan kişilerin örgüt ile özdeşleşmek veya örgüt ile özdeşleşmemek şeklinde beliren özdeşleşmek tanımı bir taraftan çalışanların örgüt kaynaklarından yararlanıp kendi performansını yükseltmesi diğer taraftan ise özdeşleşmeme durumu bireyde strese ve kendisini örgütten izole etmesine sebebiyet vermektedir. Bu nedenle de çalışan ve örgüt tarafindan en zorlayıcı özdeşleşme türü olarak görülmektedir. Bu açıdan belirişiz durumların ele alınarak üstesinden gelinmesi zorunludur (Aytaç, 2013).

\section{d. Tarafsız Özdeşleşme}

Bireyin algılarındaki yokluktan kaynaklanan bu özdeşleme, yansız ya da nötr özdeşleşme olarak da adlandırılmaktadır. Birey daha önceden deneyimlediği olumlu ve olumsuz durumlar sebebiyle yeni bulunduğu ortamda bilinçli olarak bir bağ kurmak istemeyebilir. Bu sebeple de tarafsız özdeşleşmesi olan bu bireyler, örgüte daha az katkıda bulunur. Dolayısıyla da örgütteki varlıklar ortalama düzeyde ya da yetersiz şekilde görülmektedir (Caner vd., 2011).

Kreiner ve Ashforth yaptıkları çalışmalarda, örgütün içersinde özdeşleşmek seviyeinin değişkenlikler gösterebileceğini belirtmiştir. Her ikisinin geliştirdikleri bu model, örgüt ve birey etkileşimleri açısından bakıldığında özdeşleşme ve özdeşleşmeme temelindedir (Karabey ve İşcan, 2007). 
Özdeşleşme düzeyinin yüksek, ancak özdeşleşmemenin düşük olduğu durumlarda kararsız özdeşleşme yaşanmaktadır.

Tarafsızca özdeşlemek durumunda bulunan özdeşleşmenin ve özdeşleşmeme durumunun az bulunması durumunu etkileyen faktörler, pozitif bir etki oluşturan bireyselcilik ile negatif yönlü etkisi olan örgütsel kimliğin gücüdür. $\mathrm{Bu}$ iki durum tarafsızlaşmayı artırmaktadır. Güçlü özdeşleşme düzeyini etkileyen faktörler ise örgütsel özdeşleşme ihtiyacı ve örgütsel itibardır. Bunlar negatif yönde etki ederken; sinizm, sözleşme ihlalleri ve olumsuz duygulanım pozitif yönde etki ederek özdeşleşmemenin artışına sebep olmaktadır (Özden, 2004).

\section{Ashforth ve Mael'in Örgütsel Özdeşleşme Modeli}

Ashforth ve Mael'in geliştirmiş olduğu örgütsel özdeşleşme modeli birey ve örgütlerin öncü kişilerinden etkilenmek durumunu incelemektedir. Bu modellemede özdeşleşmeler, örgütün içersindeki uygulamanın ve değerin birbirleri ile karşılaştırılır guruplara göre algılanılmış ayrımcılıklarına bağlı olarak ele alınmaktadır. Bu ayrımcılıklar kişinin benzersizce bulunmaya gereksinimlilik duyumsaması ve bununla ilgili ihtiyacını değişik alanlardaki üyelikler yoluyla gerçekleştirmesi sonucu ortaya çıkmaktadır (Temel, 2001).

Bir organizasyonun değerle zenginleşmesi durumunda onu farklılaştıran özelliği güçlü sadakat üretmesi olmaktadır; bu sayede bireyler, kendilerinin tercihini ve hedefini, örgütün tercihi ve hedefleriyle değiştirerek genişletebilmektedirler.

Ashforth ve Mael'in geliştirmiş olduğu örgütsel özdeşleşme modelinde örgütün öncü kişilerinin 2. reklâmcılık, ağızlık yolu ile aktarmak, şirketçe kontrolü yapılan iç iletişim ve dış bilgi gibi farklı bilgi kaynaklarından ortaya çıkan örgütsel itibardır. Örgütsel itibar ile çalışanlara örgüt dışnda kalanlar tarafindan örgütün nasıl göründüğü gösterilmekte, bu şekilde örgütsel özdeşleşme de etkilenmektedir.

Toplum anlamında değerlilik hususiyetlerine haiz bulunduklarına inanıldığı düşünülen örgütlere dâhil olan üyeler, bu durumdan gurur duymaktadır. Örgüt olumlu bir şekilde görüldüğünde ise çalışanlar ile örgüt dışında kalan bireyler özdeşleşmeyi en güçlü şekilde yaşamaktadır. Çünkü 
insanların öz saygılarını artırmak amaçlı kısmen de olsa gurupla özdeşleşmesi elzemdir (Karalar, 2015).

Örgüt öncülü olan kişilerin 3.sü örgütlerin arasındaki rekabet durumudur. Burda örgütlerdeki özdeşleme durumunu kolay hale getiren norma, değere ve farklıklara odaklanmakta, örgütle başka örgütlerin arasında bulunan rekabette grup sınırlarını daha keskin çizmektedir. Ayrıca, sosyal açıdan sorumlu olarak algılanan örgütler, örgütün çevresindeki başka paydaşın nazarında prestiji fazda bulunmakta bu durum da çalışan kişiler açısından olumlu bakımdan özdeşleşmeye katkı sunmaktadır (Glavas ve Godwin, 2013).

Örgütün içindeki rekabetin haricinde bulunan örgütün öncüsü olan kişiler örgütle ilgili özdeşleşmeye pozitif açıdan destek sunmaktadır. Örgütün içindeki rekabet sadece ama sadece örgütün içindeki yöneticilerce yetkili bir şekilde kontrol altında tutulabilir ve yönetilebilir ise, çalışanların özdeşleşmeyle ilgili seviyesinin yükselmesine imkan sunulacaktır (Knippenberg ve Schippers, 2007).

\section{Sonuç}

Çağımızda örgütle ilgili özdeşleşme tanımına yönelik olarak yapılan birçok tanımlamanın bulunduğu görünmektedir, bu durum doğal olarak dikkat çekicidir. Zira örgütsel özdeşlemenin dinamiği yalnızca üst yönetici kadroları değil sadece, aynı zamanda tüm çalışan kesimleri de doğrudan veya dolaylı olarak ilgilendirmektedir.

Bu tanımlamaların bir bölümü bireyin kendisini örgüt fonksiyonlarının bir uzvu şeklinde görmek, örgütün kendi namına yönelik aidiyet değer ve normlarını içselleştirme gibi bilişsellik yönünün güçlü olduğu boyut ile ilişkilendirilen kavramsal çerçeveler olur iken, bazılarıysa guruba ait olmaktan onur duyma, gurur hisstme, üyeliğin kaybedilmesi durumunda psikoloji açısından dekadans yaşama gibi duygu ve duyuş alanlarının salt boyutlarında ierdelenmiştir. Söz konusu boyutların dahil edilmek suretiyle özdeşleşmeyle ilgili kavramın diğer boyutlarla da ilişkilendirilmiş olduğu tanımlamalara rastlama da pekala imkan dahilindedir.

Örgütlerin pek çoğunda görüldüğü şekilde eğitim kurumlarında da özdeşleşme kavramının ehemmiyetli konumu bulunmaktadır. Okullarda görevli öğretmenler düşünüldüğü zaman, şayet 
kendi bulunduğu ve görev yaptığı okulda örgüt içersinde kurumsal bir özdeşleşme seviyesi fazdaysa bu öğretmenler öğrenciler ve dolayısı ile okulun başarmasını şahsi başarması şeklinde görülmekte ve başarısızlık durumuna cevap bulma hususunda çabalar içersinde bulunmaktadır. Bunun yanı sıra, her eğitim örgütü kendine yönelik bir örgüt iklimi oluşturur, dolayısıyla da her kurumda örgütçe kararlar alınmaktadır.

Örgütle ilgili karar süreçlerinin örgütün çalışanı olan kişilerce uygulanılmasında öğretmen olarak görev yapan çalışanların kurumsal özdeşleşmeyle ilgili düzeyleri mühim şekilde görünmektedir. Zira öğretmen olarak okullarda görev yapan kişiler, eğitimsel örgütlerin en yetkili uzuvları olarak genel anlamda kabul görmektedir. Eğitimin seviyesini çok daha fazla kalite ve nitelik yönü ağır basan bir hâle getirme amacıyla öğretmen olarak okullarda görev yapan kişilerin okulları ile özdeşleşim kurmaları çok mühim bir gerekliliktir. Çalıştı̆̆ ve görev yaptığı okulla özdeşleşim kuran öğretmenler, kurum kültürü ve yönetimi anlamında okula çok fazda uyumsama göstermekte ve örgüt ile ilgili hedef ve gayeleri kendisinin şahsi hedef ve gayesi şeklinde kabul etmektedir.

Kendi çalıştığ kurum ile özdeşleşen bir öğretmen bulunduğu kuruma aidiyet duygusu ile bağlanmakta, örgütün değerleri ile hedeflerini kendi değeri ve amacı olarak görmekte, kendisini bulunduğu kurumun önemli bir paydaşı olarak görmekte ve okulun kurum örgütü ile birliktelik alg1 ve hissi geliştirilmektedir.

Örgütsel özdeşleşme, eğitim-öğretim açısından bakıldığında öğretmenin okula bağlılığını ifade etmektedir. Buna örnek olarak öğretmenin ‘ben kimim?’ sorusuna verdiği yanıt söylenebilir. Öğretmenin bu soruya kendisini ve grubunu düşünerek, ortak amaçlar dâhilinde cevap vermesi örgütsel özdeşleşmeyi ifade etmektedir.

Çoğulcu zihniyete sahip olan, okulunun başarısını kendi başarısı gibi gören,yapılan eleştirilerde yapıcı yaklaşan ve çözüm odaklı olan, diğerlerinin okul için düşündüklerini kişisel algılayan öğretmenlerin örgütsel özdeşliği yüksek olmaktadır. 


\section{Kaynakça}

Ashtorth, B., Corley, K. ve Harrison, S. (2008). Identifications in organization: an examinations of fours fundamentalist question. Journal of Management, 34 (3), 326.

Balc1, A., Fidan, T., Cereci, C. Baltacı, A. ve Acar, U. (2012). Örgütün sosyalleşmesinin, örgütsel özdeşleşmeyle ve örgütsel vatandaşlık ile ilişkisi: ilk öğretim okul yöneticileri üstünde bir araştırma. Ĕ̆itim Bilimleri Araştırmaları Dergisi, 2 (2), 46.

Başar, H., (2005). Sınıf yönetimi. Ankara: Anı Yayıncılık.

Caner, T., K. Zagenczyk, Hester, T., Gibney, R., ve Fuller, J., (2011). Explorings organization on struction and the expant modelist organizationalist identifications. Journal of Social Psychology, $41(5), 1087$.

Çelik, V. (2005). Eğitimsel liderlik. Ankara: Anı Yayıncılık

Çetinkara, M. ve Çimençi, S. (2014). Örgütte adalet algısının örgütsel vatandaş davranışları üstündeki etkisinin ve örgüt özdeşleşmesinin aracılık rolleri: yapı eşitliği modellemesi çalışması. Yönetim Bilimleri Dergisi, 12 (23), 238.

Demirel, Ö. (2005). Öğretim kurumlarında dĕgerlendirme ve planlama: öğretmenlik sanatı. Ankara: Pegem Yayınları.

Glavas, A. ve Godwin N. (2013). Is theperceptions of goodnes goodenough? Explorings therelat on ship betweens perceivet corporat social responsibilityam demploye organizationalist identifications. Journal of Ethics, (114), 17.

Jones, C. ve Volpes E. H. (2010). Organizational identification: extenn dingourun derstanding of social identiti through social net works. Journal of Organizational, 32 (3), 414.

Kağıtçıbaşı, Ç. (2004). Yeni insan ve insanlar. İstanbul: Evrim Yayınları.

Kanten, P. (2012). İş görenlerde işe adanmanın ve pro aktif davranışların oluşmasında örgüts güveni ile örgüt özdeşleşmesinin rolü. Yüksek Lisans Tezi. Süleyman Demirel Üniversitesi Sosyal Bilimler Enstitüsü, Isparta. 
Karabey, C. N. (2005). Örgüt özdeşleşmesi, örgüt imajı ve vatandaş davranışı ilişkisi: bir uygulama. Yüksek Lisans Tezi. Atatürk Üniversitesi Sosyal Bilimler Enstitüsü, Erzurum.

Karabey, C. N. ve İşcan, Ö. F. (2007). Örgüt özdeşleşmesi, örgüt imajı ve örgüt vatandaşlıkları davranışları ilişkisi. Akdeniz Üniversitesi İdari ve İktisadi Bilimler Fakültesi Dergisi, 21 (2), 232.

Kaya, D., İleri, Y. ve Yüceler, A. (2017). Effects of organizational trust on identification in a university hospital in Turkey. Journal of Human, 14 (2), 2014.

Kaya, Z. (2007). Sınıf yönetimi. Ankara: Pegem Yayınları.

Knippeberg, D. ve Schise, M. (2000). Focis and correlat of organizationalist identifcation. Journal of Occupationa Land Organizational Psychology, 2 (73), 134.

Knippeberg, D. ve Schipper, C. (2007). Works group diversit. Annual Rewiwv of Psychology, 4 (58), 511.

Kreinner, E. ve Ashtorth, E. (2004). Evidence toward an expant model of organizationalist identification. Journal of Behavior, 25 (1), 27.

Miller, D., Casey, R., Johnson, M. ve Allen, M. (2000). Recons idering the organizationalist identification question naire. Management of Quarterly, 13 (4), 628.

Özdemir, A. (2010). Örgüt özdeşleşmesinin hissedilen örgüte dönük cinsiyet, destek ve kıdemsel değişkenlere göre incelenmesi. Türkiye Sosyal Araştırmalar Dergisi, 14 (1), 230.

Polat, M. (2009). Örgüt özdeşleşmesinin öncüleri üstüne bir alan çalışması. Doktora Tezi.Uludağ Üniversitesi Sosyal Bilimler Enstitüsü, Bursa.

Polat, M. ve Meydan, C. H. (2010). Örgüt özdeşleşmesinin sinik ve işten ayrılmak niyetiyle ilişkisi üstüne bir alan araştırması. Savunma Bilimleri Dergisi, 9 (1), 142.

Polat, S. ve Celep, C. (2008). Orta öğretim öğretmenlerinde örgüt adaleti, güveni, vatandaşlığının davranışlara ilişsin algıları. Kuram ve Uygulamada Eğitim Yönetimi Dergisi, 14 (2), 301.

Scott, C. R., Cheney, G. ve Corman, S. R. (1998). Developments of a structorational model of identifications in the organizations. Communication of Theorys, 8 (3), 296.

Silah, M. (2001). Eğitimsel örgütlerde hizmet niteliğini artırmak amacıyla çalışanların ödüllendirilmesi. Cumhuriyet Üniversitesi İktisadi ve İdari Bilimler Dergisi, 2 (1), 99. 
Sönmez, V. (2003). Öğretmenlik mesleğine giriş. Ankara: Anı Yayıncılık.

Sönmez, V. (2005). Eğitim felsefesi. Ankara: Anı Yayıncılık.

Temel, E. (2016). Dönüşümsel liderlikle psikoloji güçlendirmesi arasındaki ilişkide örgüt özdeşleşmesinin aracıllğı: Nazillî’deki kamusal kurumlarda bir alan uygulaması. Yüksek Lisans Tezi. Adnan Menderes Üniversitesi Sosyal Bilimler Enstitüsü, Aydın.

Tokgöz, E. (2012). Örgüt güveni, özdeşleşmesi ve vatandaşllğının davranışla arasındaki ilişkinin incelenmesi. Yüksek Lisans Tezi. Üniversitesi Sosyal Bilimler Enstitüsü, Balıkesir.

Tokgöz, E. ve Aytemiz, O. (2013). Örgüt güveni, örgüt özdeşleşmesi ve örgüt vatandaşlığ1 arasındaki ilişki: bir kamu hastanesinde alan araştırması. Öneri Dergisi, 10 (39), 69.

Tümer, E. (2010). Işletmede örgüt adaleti ve örgüt özdeşleşmesi: bir alan uygulamast. Yüksek Lisans Tezi. Gazi Üniversitesi Sosyal Bilimler Enstitüsü, Ankara.

Tüzün, İ. K. (2006). Örgüt güveni, kimliği ve özdeşleşmesinin kendi arasındaki ilişki: uygulama alanında bir araştırma. Doktora Tezi. Gazi Üniversitesi Sosyal Bilimler Enstitüsü, Ankara.

Tüzün, İ. K. ve Çağlar İ. (2008). Örgüt özdeşleşmesi kavramıyla iletişimsel etkinlik arasındaki ilişki. Yaşar Üniversitesi Dergisi, 3 (9), 1017.

Webber, S. (2011). Dualist organizational identifications impacting olientsatis factions and words of mouth loyaltys. Journal of Business, 2 (64), 115.

Yavuzer, H. (2000). Anne, baba ve çocuk. İstanbul: Remzi Kitabevi. 